\title{
Analysis of Graphic Design and Color Application in Tourism Advertising
}

\author{
Zuo Guohua \\ Fine Arts Academy of Huang Gang Normal University, 438000
}

\begin{abstract}
This paper makes a brief statement about the graphic design in tourism advertising, such as methods and characteristics of photography, graphics, computer generated graphics, painting graphics, text graphics and seal graphics. Meanwhile, this paper illustrates the emotions and cultural connotation of color. Whether the graphic design and color application in tourism advertising are good or not will directly affect the success or failure of tourism advertising. As a result, designers have to buckle down and carefully select graphic design in tourism advertising, and rationally make full use of the colors of tourism advertising. Only by designing outstanding tourism advertising, can tourism advertising publicity be fully showed, so as to improve the popularity of tourism products.
\end{abstract}

Key words: Tourism, Scenic spots, Graphics, Colors

\section{INTRODUCTION}

Tourism is a recreational activity that tourists go for long-distance sightseeing. The folk culture, local conditions and customs, social customs and so on of tourist areas will bring tourists the novelty on the vision, stimulating the their visual perception and arousing their aesthetic potentials. In today's information age dominated by visual media, tourism advertising plays a very important role in the whole tourism process. Designers eliminate some doubts on the tour information for tourists by graphics, image display and publicity. Designers use abstract, generalized and succinct language to design the tourism images in order to make it visually displayed for visitors, helpful to convey the cultural connotation of tourism products and strengthen tourists' memories of tourism products.

\section{Graphic designs in tourism advertisement}

As a special kind of tourism image transmission carrier, tourism graphics shoulder the responsibility of conveying tourism information and arousing tourists' interests, playing a communicative role between tourist attractions and tourists' aesthetic psychology, which will turn tourists' aesthetic impulse into actions. Photography pictures are the most intuitive and common tourism graphics, for they can truly and accurately present the characteristics of tourist attractions, making visitors have immersive feeling. Photography pictures are directly and indirectly applied in advertising. Direct applications can only be classified as photographic pictures, while indirect applications must be processed and produced by computer software, making some changes in color and form to present more artistic expressions. For example, while presenting the great men or heroes, the red tourism scenic spots will generally combine the scenery photograph reflecting revolutionary times with relative characters, adopting montage to transform characters into looking-up angles to enhance the advertising art effects, thus causing the viewers' emotional resonance.

In addition to the photography pictures, more painting graphics are applied. Before the appearance of photography, painting graphics is the only way of tourism advertising, the 
traditional Chinese painting, oil painting, printmaking, watercolor painting, etc., by which themes and designers' imagination can be freely and easily displayed. As a traditional Chinese cultural symbol, Chinese painting will surely first convey information of Chinese culture. ${ }^{[1]}$ For example, the propaganda painting Grasp Revolution, Promote Production created by Fang Zengxian, Xie Zhiliu and Zhu Qizhan has presented the bustling scenes of the ports ship freight in the Cultural Revolution. It played a very good publicity role at the time of the old China when photography technology lagged behind. What is more, the Wuhan snack-- poster graphics combines the traditional snacks' props with dynamic characters, really and objectively reproducing the styles and characteristics of the local traditional snacks.

In recent years, with the development of digital technology, computer generated images are widely used in tourism advertising design. Computer application software is able to conduct various post-processing to greatly improve the photography technology in the field of design. Applying vector diagram and the three-dimensional graphics software to graphic originality design in images post-processing, the images will blend into new design elements and more cultural connotation and visual tension. Therefore, the computer plays a very important part in the tourism graphic design. Computer generated graphics is characterized with advantages of performing creativity freely, modifying conveniently, as well as bright and natural colors, which photography painting can't be beyond comparison. Therefore, in recent years, computer generated graphics has the trend to replace other picture forms.

Text is one important element in graphic design. Text graphic design is characterized with intuitiveness, abstract, large amounts of information, and strong appeal. Word processing of graphic design is consisted of graphics and text. Text mainly involves content selection and layout, and font design is an integral part of the graphic design. In text graphic design, the performance of the visual tension should be paid attention to. At the same time, the readability of text is also crucial, and the following technique can be made full use of, such as strokes increase or decrease, exaggerated deformation, restructuring, abstract, decoration and so on. Thus the text graphics will have a unique shape and rich word connotation.

Seal graphics aims to publicize the tourist attractions to tourists through seal graphic designs, mainly sceneries, figures, and construction graphics. Seal is a result of productivity development to a certain stage. ${ }^{[2]}$ Seal graphics is based on traditional Chinese seal cutting art. "Chinese seal" application in the field of design has experienced a long historical evolution, from the bird printing in Qin and Han Dynasties and initialing seals in Song and Yuan Dynasties, and then to the 2008 Beijing Olympics logo of "Chinese seal, dancing Beijing". All of them combine the Chinese traditional elements with figures, animals and plants and make the design works vigorous. The combination of seals and tourism will not only be seared tourists' journey footprint, but also satisfy their aesthetic psychology needs, and it also has advertisement and collection value. Tourism seal graphics has very good functions of publicity and recording the historical time and space. Words, seal graphics and color coordination ably publicize and serve the scenic spots, and reveal the regional culture local customs and the natural landscapes of tourist attractions. Tourism seals can record beautiful historical moments for people to collect and accept as a souvenir. 
At present, the development of souvenir medals in domestic scenic spots is not optimistic. Most of them are about the natural sceneries, buildings objective of the scenic spots, while lack of local characteristics and creativities. In addition, themes are not clear and designs are dull, not conducive to the spread and development of tourism products. Most advertising graphic designs in the scenic spots lag and lack of systematic and scientific orientation for tourism advertising, as well as local characteristics and related cultural elements. The featureless tourism advertising will seriously affect upgrading of update domain in the tourism industry. So blending specific culture connotation, local features, and process characteristics into advertising graphic designs in scenic spots will improve the artistic and aesthetic qualities of advertising products, thus stimulating the development of tourism economy and culture.

\section{Color applications in tourism advertising}

The color is originally a physical phenomenon, but people can feel the emotions of color. The psychological influence of colors will unconsciously affect people's moods, because the psychological reaction to colors can cause people's associations. ${ }^{[3]}$ Colors are effective ways to convey designers' intention and emotion, and different colors will give tourists different visual perceptions, thus causing the emotional deviation. This is color emotional function. For example, red is a very festive color in Chinese eyes, representing warmth, passion and vitality, which symbolize the martyrs' blood boiling, revolutionary strength, and happiness in festivals and beauty in youth. Due to the rich connotation of red, there appears the "red tourism". It was originated from visitors' retrospect to revolutionary martyrs and the revolutionary history. The purpose of developing red tourism is to inherit revolutionary ideas and carry forward revolutionary spirits, inspire the posterity to fight and develop excellent cultural traditions in old revolutionary bases. Red tourism is unique for it must highlight its revolutionary characters and embody the spiritual things, so the design methods must be novel to avoid tediousness, thus establishing a good revolutionary image and carrying forward the fighting wills. It can also educate the posterity to cherish today's happy life and never forget the arduous struggle spirits. While green stands for youth, environmental protection, health, science and technology, representing modernists' values and yearns for life. For example, the ground army and the field team usually wear green uniforms, and urban planning often has green construction, and "green" themes in campus cultural activities are common. Some tourism constructions and places also adopt green as the main color to alleviate people's eye fatigue. Moreover, the yellow desert landscapes, the green grassland landscapes and the blue ocean tour all manifest rich emotional colors in the tourism images.

The implication of colors is a expression based on tourists' colorific feelings and associations, possessing both historical precipitation and specific cultural connotation, which are inherited in the relatively stable cultural environment. Hence it is a unique way of thinking and embodies the human emotional experience and national feelings. For example, purple has elegant and noble implied meaning, full of myth, which Is western emperors' clothes color. Because different nations and regions have different imagination and demands for colors, designers should pay attention to blending color implication and regional culture 
elements into design works to make them unique and novel, so as to meet most tourists' psychological needs. For instance, red represents festival, optimism and revolution. In the ancient China, red also had the function of expelling evil. The walls of the palaces and temples, and officials' clothing are all most red, which are the so-called "vermilion gates ", "vermilion clothing". In the west, red symbolizes sacrifice, brutality and bloodshed, such as "a red battle"--bloody battle, "red alert"-- air raid alarm, "a red revolution" --communist revolution, etc. In China, white stands for purity, brightness and filling, and it is used as the color of the Yin and Yang fish of Tai Ji Diagram in Taoism, representing the unity and opposite between Yin and Yang, interdependence and mutual transformation. In the eyes of westerners, white is the symbol of power and status, such white-collar workers in the UK and the White House in the United States, and white stands for purity and peace in France. The same color in different audience's eyes also has different preferences and emotion reflection. Designers should put special emphasis on the colors' contemporary and unique meanings, so as to seize the characteristics of modernists' aesthetic psychology and attract more tourists for tourist attractions.

Colors also have strong cultural connotation. In tourism advertising design, the color design and deployment can reflect its local culture, thus making the works unique and interesting as well as stimulating their desire to travel. The water culture of Dujiang Dam possesses strong regional features, including hydrology, water theology relics and so on, such as "Two Kings Temple", " Fu Long Temple ", "Viewing Deck", etc. which are equipped with strong regional culture characteristics and religious theology. Colorful Yunnan is one of the world famous brands of Kunming in Yunnan Province. Its poster color design uses the batik black in Yunnan and three primary colors for blending, so that visitors can feel the strong local cultural characteristics. Our ancestors left behind a large number of cultural heritage, such as Confucius Temple, the forest of steles, Terra Cotta Warriors, Overlord Vessel, Chinese bells and so on, all of which have unique cultural connotation and color forms and attract many experts, scholars and travel enthusiasts. Designers should make full use of Chinese classical colors when making color composition, and adopt traditional painting forms, such as engraving painting, traditional Chinese painting, decoration painting, etc. as many as possible.

\section{CONCLUSIONS}

In conclusion, whether the graphic design and color application in tourism advertising are good or not will directly influence success or failure of tourism advertising design. It is necessary to combine the history and humanities background of tourist attractions and properly choose graphics expression methods. Different visual impressions of luxuriant, warm, pure and fresh and lively landscapes should be expressed in different colors, so as to present different visual feeling to visitors. Designers should start from the overall and comprehensively consider both the graphic design of tourism products and colorific emotions, associations, implications and cultural connotation. As a result, advertising with the era characteristics and visual appeal can be designed. At present, there are still many problems in graphic design and color application of tourism advertising in our country. Therefore, designers are supposed to give full play to their wisdom and spare mutual efforts to make tourism advertising design novel, unique 
and full of rich cultural connotation.

\section{References:}

[1], [3]. Li Jiantao, China Travel Poster Design Researches -- Hubei tourism [D] Hubei
University of Technology, 2011

[2] Yi Yang. Seal Symbols Application in Visual Images of Hubei Chu Cultural Tourism, [D] Hubei University of Technology, 2012 